University of Nebraska - Lincoln

DigitalCommons@University of Nebraska - Lincoln

To Improve the Academy

Professional and Organizational Development

Network in Higher Education

1996

Making the Transition from Soft to Hard Funding: The Politics of
Institutionalizing Instructional Development Programs

Mary L. Everley

Jan Smith

Follow this and additional works at: https://digitalcommons.unl.edu/podimproveacad

Part of the Higher Education Administration Commons

Everley, Mary L. and Smith, Jan, "Making the Transition from Soft to Hard Funding: The Politics of Institutionalizing Instructional Development Programs" (1996). To Improve the Academy. 356.

https://digitalcommons.unl.edu/podimproveacad/356

This Article is brought to you for free and open access by the Professional and Organizational Development Network in Higher Education at DigitalCommons@University of Nebraska - Lincoln. It has been accepted for inclusion in To Improve the Academy by an authorized administrator of DigitalCommons@University of Nebraska - Lincoln. 
Everley, M.L., \& Smith, J. (1996). Making the transition from soft to hard funding: The politics of institutionalizing instructional development programs. In L. Richlin (Ed.), To Improve the Academy, Vol. 15 (pp. 209-230). Stillwater, OK: New Forums Press and the Professional and Organizational Development Network in Higher Education. Key words: Change Strategies, Faculty Development Role, Funding, Instructional Development Programs, Organizational Culture.

\section{Making the Transition from Soft to Hard Funding: The Politics of Institutionalizing Instructional Development} Programs

\section{Mary L. Everley}

\section{Jan Smith}

University of Minnesota-Twin Cities

The institutionalization of grant-funded instructional development programs is a political process. This paper reviews the experiences of programs that have both failed and succeeded to cross the hard-to-soft-money divide and the literature on planning and change in higher education, and offers strategies that will encourage institutionalization. Changing institutional culture, building a strong advocacy group, and gaining the support of key administrators are essential to program continuance.

Many instructional development initiatives begin as pilot programs funded by foundation grants. Institutions, having pledged to cover a portion of a program's overhead expenses, proudly announce that 
another grant has been received. Three years down the road, however, when the time comes for an institution to assume funding for the program, the administrative support and commitment that heralded the program's arrival have dissipated or disappeared (Millis, 1994).

Planning for program continuation is a phase of program development that is often given contingency status and deferred until the fiscal end of the program cycle looms and ongoing financial support appears tentative. Berry (1991) contends that strategies for continuation should be devised when the program is initially conceived and given equal attention with plans for implementation and evaluation. If, at the outset, program planners adopt the attitude that they are spending their own or their institution's money, rather than "'free' money provided by a distant, impersonal 'funding agency,"” (p. 2) they will be more motivated to consider the long-term viability of the proposed enterprise.

Program discontinuance is disappointing and leaves a gap in the services an institution provides its faculty and students. Why, then, do instructional development programs that seemingly meet the traditional reputation, resources, outcomes, and value-added quality criteria, and that serve their constituents well, fail to make the transition from soft to hard funding? The answers to this question are often institution-specific and are always political. Program viability, according to Gumport (1993), is a "struggle for legitimacy and power" (p. 288). "Centrality to mission, quality, and financial cost/benefit" are only three of the criteria administrators use to determine academic program continuance and are "loosely coupled to decisions about cuts." (p. 290). The actual reasons programs are or are not continued are often based on subjective judgment, rather than objective data.

Levine's (1980) institutionalization-termination model offers a parsimonious explanation of program success and failure, attributing them to compatibility and profitability. Compatibility is the "degree to which the norms, values, and goals of an innovation are congruent with those of the host" (p. 17). Profitability assumes two forms: self-interest and general. "Self-interest profitability is that which motivates the individual subunits and the individual staff within an organization to adopt an innovation. General profitability is that which motivates an organization to choose or maintain an innovation, but is 
such that neither subunit nor individuals would adopt it themselves" (p. 19). Levine's response, then, to the question, "Why does an innovation fail?," is "Because it is either incompatible or unprofitable...The degree of failure is greater if it is unprofitable" (p. 160).

Convincing administrators that instructional development programs are worthy of permanent status within institutions, that they are not just window dressings paid for by empathetic foundations, involves changing attitudes toward the value of good teaching and faculty/TA development. Change in higher education has been likened to moving a cemetery or turning a battleship; it is notoriously difficult and slow, but as Hefferlin (1969) recounts, it does happen.

The literature on change and innovation (e.g., Lindquist, 1974, 1978; Conrad, 1978; Levine, 1980; Martorana \& Kuhns, 1978; Nordvall, 1982; Seymour, 1988) provides direction and advice for those attempting to introduce or secure permanent funding for instructional development programs. Instructional development programs are intimidating to some because they threaten the status quo. Thus, building support for them is a politically-laden endeavor. Reports from instructional development specialists who have already gone through the process lend the pragmatic perspective to the theory presented in the literature.

In this paper, we put forth ideas for helping instructional development programs make the transition from grant to institutional support. Our suggestions apply primarily to public institutions, but may be useful for private institutions as well. We begin by examining the research on program planning, and change and innovation in higher education. The discussion then turns to building support for programs and general institutionalization strategies. Throughout the paper, we incorporate experiences and recommendations from our own institutionalization efforts with the University of Minnesota's Preparing Future Faculty (PFF) program and those of selected federally- and state-sponsored education programs. Minnesota PFF was created from two grant-initiated programs, the Teaching Opportunity Program for Doctoral Students, funded by the Bush Foundation, and Preparing Future Faculty, funded by the Pew Charitable Trusts and part of a national PFF project administered by the Association of American Colleges and Universities and the Council of Graduate Schools. 


\section{The Status of Instructional Development Programs}

Proclaiming that teaching is receiving renewed attention and emphasis at colleges and universities is not new. Numerous authors (e.g., Davis \& Minnis, 1993; Gaff, 1994; Gaff \& Simpson, 1994; Millis, 1994) have recounted the death and resurrection of instructional development programs during the 1970s, 1980s, and 1990s. The reasons behind the current calls to focus on instructional development programs include the following: acknowledgment by doctoral graduates that their pedagogical knowledge is inadequate and that they arrive unprepared for the teaching aspect of their new faculty role, outcries from the general public that undergraduate students are subjected to poor instruction from both professors and TAs, calls from state legislatures for teaching accountability, and a delayed recognition by institutions of a) the competitiveness of the job market for recent $\mathrm{Ph}$.D.s, and b) the increasing diversity of the student population and the multiplicity of student life experiences and learning styles.

Currently, there is a general sense in higher education that the pendulum has swung and that central administrations are more supportive of instructional development programs than in the past. Correspondingly, faculty interest has increased and a larger percentage of instructional development programs are operating on institutional moneys instead of grant moneys. Doctoral student programs, like PFF, and courses in pedagogy are being established. (For examples of other doctoral student programs see Lambert \& Tice, 1993.)

Despite the encouraging reports of revived commitment to instructional development, one need not look far to see instructional development programs, or particular program initiatives, that have not survived this time of relative teaching prosperity. Colleagues at the University of Washington, The Ohio State University, the University of Pittsburgh, and the University of Minnesota, to name just a few institutions, have experienced program elimination, down-sizing, or been forced to reorganize. The need to effectively and efficiently plan instructional development programs and to sell them to skeptical administrators is as important as ever. Programs that are funded by 
grant dollars continue to be threatened with extinction once the soft money runs out.

New faculty and TAs are often advised to build in solutions to potential problems by iterating on their syllabi how touchy topics like extra-credit work and attendance will be handled. They are told that solutions are best determined before problems arise. This same wisdom can be applied to grant-supported instructional development programs. Careful consideration during the planning process can help ensure that programs will be institutionalized at the end of their grant periods.

\section{Program Planning}

Optimally, program planning follows a logical progression. It is its seemingly intuitive nature, however, that encourages people zealous about a program idea to overlook some of program planning's most basic tenets. Actions that would foster program adoption or continuance are neglected or forgotten.

Fretz's 1993 model for faculty development programs asks planners to consider their program's fit with the mission and priorities at all levels of the institution - the department, the college, the provostial unit, etc.; arrive at a vision for the program-what it will be and how it will get there; assess institutional and prospective participant needs; set program priorities; choose activities to meet the needs; conduct a formal program assessment; and use the feedback received to modify and fine tune the program (pp. 102-106). (See also, Bledsoe, 1994.) In reference to Fretz's model, Reich (1994) suggests that priorities be organized on the bases of feasibility: "(a) What is possible within the bounds of the doer(s) (i.e., without added resources or anyone's permission); (b) what requires added resources; and (c) what requires both resources and approval by some high administrator or organization" (p. 512).

In his monograph on the program development process, Seymour (1988) draws upon the literature pertaining to "innovation in organizations, strategic planning, and program evaluation" (p. iii). He highlights the interplay between the external environment and its changing demands and the capabilities and appropriateness of institutions to 
respond to those demands. Some of the more helpful tips that he offers for program planning that have not been mentioned above, are: "Coordinate all activities related to program development through a limited number of persons or offices....Integrate institutional research into all procedures for program development....integrate planning for academic programs with planning for finances and facilities" (p. viii-ix). Cost and demand are, perhaps, the overriding issues.

Walsh and Meade (1981), Seymour (1988), and (Berry 1991) stress that program planners should think seriously about where their program will fit into the mix of programs already offered by the institution and how existing resources can be incorporated into the program's design. Is there a niche that has not been filled or will the program duplicate the efforts of others? Hill (1981) asks planners to consider "effects in the aggregate" (p. 1). What is the overall effect on faculty and TAs of the combined efforts of the many programs on campus that address teaching and learning? Participants and administrators should not be forced into the no-win situation of choosing between related programs when allocating their resources and time.

An illustration of the duplication and overlap that can occur if programs go unchecked, is found in Watson and Grossman (1994). They counted more than 20 organizational units on their campus that were involved in faculty development work. They regarded this fragmentation as "counterproductive" (p. 467) and describe why:

First, the variety of activities sponsored by these numerous programs inundate faculty with an uncoordinated, unintegrated mish-mash that fails to give a coherent structure to faculty development generally and diminishes the attractiveness of the individual activities singularly. The multiplicity of individual programs means that help is rarely just a phone call away because a faculty member doesn't know whom to call. One call can escalate into a frustrating series of calls to find help for even a relatively simple request.

Second, the fragmentation of resources-equipment, funding, and personnel-can result in few of the operations performing up to their potential even though the total resource commitment to all programs is substantial. The consequence can be a competition for the scarce resources available, accompanied by turf protection and an ethos that diminishes rather than encourages cooperative efforts. (p. 467) 
A concept from the systems literature that is useful for helping planners comprehend their program's fit and interrelationship with current offerings, is that of tight and loose coupling (Birnbaum, 1988). Elements in a system are linked or coupled; the tightness or looseness of that coupling is reflected in how strongly a change in one element affects change in another. In other words, if a change occurs in program $\mathrm{X}$, what effect does that have on program $\mathrm{Y}$ ? The more variables programs share, the more tightly they will be coupled.

Planning for institutionalization requires a vision of an instructional development program's relationship to its institution's culture, priorities, needs, and established programs. The further development and amplification of some of the planning elements that have special significance for grant funded programs is necessary.

\section{Institutional Fit}

How does the instructional development program fit with the institution's culture? Where on the list of institutional priorities does good teaching lie? According to Mortorana and Kuhns (1978), "the value structure of any institution includes a formal or informal ranking of goals which results in a hierarchy of aspirations or priorities in the institution" (p. 1). They label the gap occurring between the level to which an institution aspires for a goal and what it has achieved as "goal hiatus" (p. 1), and suggest that the gap constitutes an area for program development. If good teaching is high on the priority list, then the gap will loom larger and more imperative in administrators' minds and be more likely to command attention and commitment.

The priority assigned to good teaching within an institution depends on an institution's culture. A large number of researchers, most notably for the purposes of this paper Schein (1985), Tierney (e.g., 1988), and Bergquist (1992), have studied culture in organizations. Culture, says Bergquist, "provides meaning and context" (p. 2) for a group. It is "established around the production of something valued by its members. . . The culture of academic organizations must thus be understood within the context of the educational purposes of collegiate institutions" (p. 3). An institution's programs "are always 
directed toward the institution's purposes and derive from its cultural base" (p. 3).

The task of the individuals proposing an instructional development program is to discern how consonant their program will be with the culture and priorities of the institution, and where within the institution's subunits, it best fits. With which unit are its purposes and methodologies most congruent? How can the program be shaped so that it complies with the institution's mission and furthers its objectives?

In light of this admonition, PFF has anchored itself to the University of Minnesota's much publicized planning document for the next century. The document prominently displays the goals of education and preparing "a new generation of the highest quality professionals, researchers, and faculty for the state and nation. The university will enhance its teaching pedagogy programs for graduate and professional students who aspire to careers in teaching." In its program reports and funding appeals, PFF repeatedly makes reference to the direct links between its efforts and the University's stated goals and priorities.

Obviously, the response and enthusiasm of faculty and administrators to instructional development programs will vary from institution to institution and over time. The extent to which program supporters are able to convey their program's fit with the institution's vision for itself and its strategic plan for the future, will also have an impact on administrative decisions. During the grant period, those responsible for the program must continually reassess where the program lies in relation to the aforementioned concerns.

\section{Assessing Program Demand and Participant Needs}

Who will be a program's target audience? Program planners must determine the demand for their program and the needs of the institution and prospective participants. What is critical to know is approximately how many people will participate and what their characteristics are. One place to start, when attempting to determine need, is with records from past endeavors and other data that has been gathered. An institution's office of institutional research or planning is a ready resource of information. 
It may be necessary to survey possible participants to better understand their needs and desires for a program (e.g., Watson \& Grossman, 1994). PFF surveyed faculty not only to discern what resources were already in existence for doctoral student preparation in teaching and what additional resources were desired, but also to determine who would support pedagogical course work for doctoral students and whose graduate students would be encouraged to participate in a voluntary teaching program.

An alternative to paper surveys, is to meet with key groups of faculty or TAs to get a personal sense of their needs. This, though labor intensive and expensive, can be more effective (Walsh \& Meade, 1981). Lindquist (1974) asserts that the greater the number of both personal and organizational needs that an innovation addresses, the more likely is its adoption (p. 35).

Walsh and Meade (1981) summarize the relationship between needs and program survival, "[their program's] front-line approach to institutionalization is a straight-forward and simple one: provide needed services in an effective and efficient manner, and recipients of those services will justify, if not demand, continuation and eventual institutionalization of the service-providing entity" (p. 64). By meeting participant needs, particularly those that are not being met elsewhere, a program builds dependence on itself.

\section{Program Assessment}

It can have two other purposes: to provide feedback for improvement (formative evaluation), and to produce evidence for administrators that a program deserves to be continued (summative evaluation).

Periodic assessment must be built into the original program plan; effective programs, like effective teachers, continually take the pulse of their participants and students. If positive program results are being achieved and resources are being used efficiently, this information can be supplied to administrators throughout the grant period. Fleischman (1980) recommends devising a "periodic schedule for providing project feedback based on formative evaluation to decision-makers" ( $p$. 3). Institutional budgets, depending on the particular college or university, are developed from several months to several years ahead of 
time, and a last minute request for funds will probably not be granted. As part of assessment planning, program developers will need to consider who they will give their evaluation results to and when. (Fleischman also advises that program planners regularly assess their institutionalization efforts and schedule.)

Multiple assessment strategies using qualitative and quantitative indicators should be employed. Different types of data (e.g., descriptive statistics showing program participation or comments from focus groups) will be valuable for various purposes. Traditional evaluative criteria that instructional development specialists may want to compare their programs to are quality, need, demand, and cost (Conrad \& Wilson, 1985). Programs should always be evaluated against their own and the institutions' objectives.

Walsh and Meade (1981) cite "continuous self-evaluation [and] careful analysis of all facts of the operation" (p. I) as characteristics of their successful institutionalization effort. Judiciously examining all aspects of a program can help program planners better understand their product and how to market it.

\section{Change}

Planning and implementing an effective program is not enough to ensure program continuance. Institutionalization is a political process and begins with convincing administrators that a permanent change in an institution's program menu is in the institution's best interest. Attitudinal change must occur, and at least one administrator must be willing to champion and fund an instructional development program that some faculty may view as counter to their primary role as researchers.

The process of change in higher education has received a great deal of attention in the literature. This brief explanation serves as an introduction to some of the salient issues as they relate to the institutionalization of grant-based instructional development programs. Readers interested in learning more about change and innovation should consult the full texts. See, for example, Hefferlin (1969); Martorana \& Kuhns (1975); Conrad (1978); Lindquist (1978); Levine (1980); and Nordvall (1982). 


\section{Origins of Change}

Perhaps the best place to begin when trying to understand change, is with what causes or prompts it. Change can be planned or unplanned. External pressure and the activities of peer institutions are primary change stimuli. (Consider, for instance, how the mandatory use of computers in business and industry has altered the college curriculum.) Levine (1980) says that the "likelihood of change is enhanced when there is a crisis in the environment, when people have a shared interest in change, when there is a power imbalance in the environment, when the environment has experienced structural changes, and finally when it is consistent with the zeitgeist or spirit of the times" (p. 6).

Conrad (1978), when studying curricular change, concluded that "administrative intervention" is necessary for change to take place (p. 111). Interest groups may have the desire for change, but an administrator must serve as the change agent because he/she holds the requisite power and opportunities for action. Conrad also deduced that while change may or may not result from conflict, change will cause conflict (p. 108). Savvy administrators will attempt to manage the change process so that it remains controlled.

Institutional fit, culture, and change all fall within administrators' purviews. According to Levine (1980, p. 13), administrative approval and institutionalization confer legitimacy on a program. Schein (1985) opines that

the most powerful primary mechanisms for culture embedding and reinforcement are (1) what leaders pay attention to, measure, and control; (2) leader reactions to critical incidents and organizational crises; (3) deliberate role modeling, teaching, and coaching by leaders; (4) criteria for allocation of rewards and status; (5) criteria for recruitment, selection, promotion, retirement, and excommunication. (p. 225)

Conversely, "other powerful signals that subordinates interpret for evidence of the leader's assumptions are what they observe does not get reacted to"'(Schein, 1985, p. 225.). Kaczynski (1993) recounts his institution's experience with a drug education program that was supported by a grant from the Fund for the Improvement of Postsecondary Education (FIPSE). The intention was that the institution would 
assume funding for the program at the end of the grant period. The only time the top administration paid attention to the drug education program was when a drug-related arrest was made on campus. When the publicity subsided, the program was again ignored. Permanent institutional financial support was not forthcoming.

Berry (1991) includes "establish the clear, strong documented support of your Chief Executive Officer at the outset, and work hard to maintain this support through the funding period" (pp. 3-4) as another of his effective strategies for project continuation. In the project he worked with, the planners made it clear to the president at the outset that the program's first five years would have little longterm benefit for the institution unless the institution "recognized clearly and planned effectively" (p. 4) for institutionalization. They obtained a letter from the president specifying the monies the institution would commit to the project once the grant ran out and appended it to the initial grant application.

As part of the PFF institutionalization effort, and prior to the resubmission of the Bush Foundation grant, the program director visited associate deans, deans, vice presidents and provosts to acquaint them with the participation of doctoral students and graduate faculty from their units in PFF activities and to ask for their help in supporting the continuation of the program. These administrators then facilitated meetings with their peers to discuss support for the program. From these series of meetings, the PFF program director was able to chart individual administrator support of the program for the resubmission proposal and secure representative letters from deans and provosts in support of program continuation to attach to the proposal. Given the strong assertion of the foundation president prior to resubmission that renewal of the grant was contingent on progress toward institutionalization, this public relations campaign was crucial to the future of the program.

\section{The Change Process}

An instructional development program will become a part of an institution's permanent program portfolio only through the process of institutional change. Nordvall (1982) succinctly summarizes the 
change process and several of his recommendations reinforce the planning considerations mentioned earlier. He claims that the factor that most influences the success of a change effort is an "organization's receptivity to change" (p. 2). That receptivity is affected by the organization's structure, culture and history. (For an extended discussion of how organizational culture influences change, see Bergquist, 1992, chap. 11.) Nordvall (1982) urges that a proposal for the innovation or change have input from a large number of sources. Further, the proposal should

show that the new idea does the job better, is consistent with the structure and norms of the institution, is easily understood, can be instituted on a trial basis, can be adopted in part, and will have results that are easily assessed. A proposal should address both the needs of the organization and the personal interests of its members. The reward for individuals should be explicit.

In mounting a campaign to gain approval of the proposal, the forces that facilitate or hinder approval should be identified and their strength and importance measured. It is better to try to reduce resistance to change in various areas than to have the forces favorable to the plan exert stronger pressure for its adoption. Skillful people will be needed to lead the change effort. They will need to obtain the support of key administers and faculty, groups on campus, and if appropriate, external groups. (p. 3)

Lewin's (1951) concept of "force fields" can stimulate thinking about the forces working for or against the institutionalization of a program. For any given process, there are always forces pressing for or against it. The forces balance one another and result in a level of equilibrium. When the pressure for or against a process increases or decreases in strength, that balance will shift and a new level of equilibrium will be established.

Martorana and Kuhns (1975) further refine the concept. They postulate that the forces influencing change and the adoption of innovations include goal hiatus (as mentioned earlier in the section on institutional fit), and personal and extra personal forces (p. 177-78). Personal forces are the influential people within and associated with the institution (e.g., the chairman of the faculty senate, the provost, the trustees) and those people affected by the institution (e.g., students and 
the general public). Extra personal forces encompass influences such as facilities, state and federal regulations, and institutional precedent.

The degree of pressure behind these forces will influence program chances for institutionalization. The pressure will fluctuate over time with changes in the external environment and with shifting personnel and priorities within the institution. A periodic force field reassessment is necessary during the grant period. The forces acting for or against institutionalization may be different three years down the road than those identified when the initial grant proposal was submitted.

\section{The Pace of Change in Higher Education}

It is understandable why certain groups or individuals may be resistant to change or particular new programs, but why does change occur so slowly in higher education institutions? Summarizing the early literature on change in organizations, Nordvall $(1982$, p. 6$)$ cites these reasons for resistance to change:

1. Inertia -reliance on patterns of known behavior

2. Conformity to organizational norms

3. Desire to maintain coherence-avoidance of changes in one area that necessitate unwanted changes elsewhere in the system

4. Vested interests-resistance to ideas that threaten the prestige or economic livelihood of individuals

5. The sacrosanct-development beyond organizational norms of taboos and rituals that cannot be violated

6. Rejection of outsiders -avoidance of change that comes from external pressure or ideas

7. Recruitment of similar members-attraction by organization of persons who agree with the organization's activities

8. Clinging to existing satisfactions-finding these satisfactions especially comfortable when compared with the fear of the unknown Colleges and universities, with their fragmentation and horizontal shared-power structures, are designed to "prevent precipitous change" (p. 7). The autonomy of faculty members means that change will come about incrementally as faculty, one by one, then department by department, ascribe to an innovation (Hefferlin, 1969; Jones \& Lewis 1991). 
The fact that it is research, not innovation, that is rewarded at many institutions, further impedes the process.

Seeking permanent funding for an instructional development program in the traditional fashion is slow and time consuming. It is, however, because of faculty devotion to process, best to follow the appropriate channels (Bruenig, 1980, p. 161). Programs that are approved quickly and surreptitiously will typically not be looked upon favorably by faculty (Nordvall, 1982, p. 35), and support from faculty in the future is essential. Lindquist (1978) recommends that a new program or idea be aligned as closely as possible - without compromising the program - to what is already known to be acceptable or traditional (p. 23).

\section{Change Models}

Several change models and theories were proffered during the late 1960s and 1970s. Those models, as summarized by Nordvall (1982) include: rational planning, problem solving, social interaction, political, linkage, and adaptive development. In the rational planning model, the assertion is that a "good idea presented with rational convincing arguments can win acceptance" (p. 1). The problem with this model is that people and organizations are not always rational. A sound and plausible idea can be derailed, for example, by a powerful professor who has a grudge against one of the program organizers.

The second model, problem solving, focuses on the human elements and the relationships within organizations. To bring about change requires improving the individual and group dynamics. The concern is whether changing individual relationships will effect change in the entire organization (p. 2).

The next two models, social interaction and political, or an amalgamation of the two, may be the models most relevant for those attempting to institutionalize instructional development programs. In the social interaction model, "efforts are aimed at convincing opinion leaders within the organization to try a new idea. The assumption is that the idea will spread from opinion leaders and innovators to other, less adventuresome people [italics added] in the organization" (p. 2). This model, Nordvall points out, was derived from the research on the 
spread of technological innovations, and is sometimes seen as not applicable to the spread of non-technological ideas.

A concept from the social interaction model of which instructional development specialists should be mindful, is that in every organization, people will adopt new ideas, innovations, etc., at varying rates. A very small group will readily embrace a new idea. The majority of people will be hesitant and will require additional information or evidence before supporting the innovation. Early adopters are easily influenced by advertising and other impersonal methods; later adopters require more personal contact to bring them into the fold (Lindquist, 1978, p. 4).

The political model, as interpreted by Nordvall, traces change as moving along a slightly different path. It "emphasizes the process by which interest groups within the university influence the authorities [italics added] to adopt changes. Activities include building coalitions, getting the ear of important people, applying pressure, etc." (p. 2). As explained earlier, a group must convince a person in power that its need is legitimate. It is then the person in power who acts as the "gatekeeper" (Lindquist, 1978, p. 8) and puts the concern before the appropriate authorities. The problem with the political model, notes Nordvall, is that "change that emerges from a conflict atmosphere in a college or university is vulnerable; the losers generally have enough independence to frustrate the goals of the winners" (p. 2).

The final models, linkage and adaptive development, are practical syntheses of the other models. These models acknowledge that change is influenced both internally and externally and seldom follows a strict pattern. The model that is most appropriate for inducing change favorable to institutionalizing an instructional development program will depend on the institution's and the program's structure and goals. Who and when to approach with a proposal will vary with the cast of characters and how open the institution is at that time to change and innovation.

\section{Building Support}

Support for an innovation can be built, as theorized in the change models, from the bottom up or from the top down. The importance of 
garnering administrative support has already been discussed. Administrators, ultimately, determine whether an instructional development program will be institutionalized. Involving them in the entire innovation process - from planning, to implementation, to evaluationand keeping them constantly apprised of the program's evolution will increase their awareness of and stake in the continuance of the program.

The nature of higher education, however, with its faculty autonomy and first-among-equals attitude toward administrators, is such that administrative dictums are not sufficient to build enduring support for a program. For programs to survive, they must also have the endorsement of the faculty and staff, and sometimes the students (Gaff \& Simpson, 1994; Millis, 1994). "The response of primary client groups to services offered," according to Walsh and Meade (1981), is the "most important indication of... [a program's] long-term legitimacy and survival" (p. 4).

Like administrators, when faculty feel a sense of ownership of an instructional development program, they will be more inclined to advocate for the program (Reich, 1994). Faculty, too, should be involved with the project or program from its inception. Bina and Hull (1978), Millis (1994), and Walsh and Meade (1981) recommend that instructional development programs have advisory boards or committees composed of faculty members.

Lindquist (1974) describes faculty opinion leaders as "those persons to whom others turn for good advice on campus issues" (p. 336). They have the power to sway the opinions of their colleagues. Actively recruiting these individuals to be an integral part of an instructional development initiative is to a program's political advantage. (If some faculty opinion leaders express opposition to or concern about the program, their concerns should be addressed.) PFF found that faculty members who served as official mentors to students in the program quickly became strong and vocal proponents for the program.

It is essential that a grant-based instructional development program assemble a permanent phalanx of defenders (Hill, 1981). Administrative turnover is not uncommon and the support for a program can go out the door with a particular provost or vice president. The people who benefit from the program will be the ones left to speak for 
it. Good relationships with companion programs will increase the numbers of backers a program has when the time comes for institutionalization.

Public relations efforts go hand in hand with building support for a grant program. The university and higher education communities should be informed of a program's activities and accomplishments through the campus newspaper, speeches to campus and community groups, presentations at conferences, etc. (Involving program participants-faculty members or graduate students - in the presentations is sometimes more persuasive than using only program staff.) Programs should try to place members of their staffs on important university committees and task forces. A program may want to hold an open house which highlights its accomplishments and draws attention to its existence.

\section{Additional Efforts Toward Institutionalization}

The preceding sections examined many steps and efforts toward institutionalization. The advice and experience of authors whose projects have been through the institutionalization process were incorporated where relevant. The reports of $\mathbf{4 5}$ grant makers funded by the Fund for the Improvement of Postsecondary Education of the U.S. Department of Education (Marcus, 1990; Marcus, Cobb, \& Shoenberg, 1993) suggest a wealth of strategies for grant institutionalization. Creating ongoing course work or degree programs to continue educational opportunities offered through the grant, and integrating workshops, course work, or course components into existing curriculum to provide offerings not previously available, are examples of their strategies.

Other general advice that is offered by veterans of the institutionalization process includes focusing on awareness activities in the early years of the grant and on user capacity building activities in the later years (Walsh \& Meade, 1981). Avoiding "focusing on the funding agency's goals.... [and] instead [focusing] on the actual problem you want or need to solve," is recommended by Berry (1991, p. 9). Defining "individually for each critical resource what will be needed and how this can be provided beyond the funding period, "is proferred 
by Berry, as well. Positioning an instructional development program as directly as possible under a powerful administrator will give it more direct access to attention and funds.

\section{Conclusion}

There is no perfect recipe for institutionalizing instructional development programs, no fail-safe set of instructions that ensure that effective, efficient, and well-supported programs become permanent institutional fixtures. Institutionalization is dependent on the support of key administrators and where a program fits into an institution's current and future visions of itself. The role of the instructional developer is to help shape that vision and to plant the seeds of positive attitudinal change toward the importance of good teaching. Reducing resistance to change is a key part of this process and of institutionalization.

In its institutionalization effort, PFF has capitalized on the current push for improved undergraduate teaching and the university's own publicly stated accountability measures. The program director has worked intensely to gain faculty and administrative buy-in through individualized meetings and the presentation of participation data. Students and faculty mentors are vocal advocates for the program and have greatly aided in publicity and recruiting. The program's national connection has provided additional local visibility. PFF has been able to present itself as offering both institutional and individual rewards and as a resource-efficient means for exposing doctoral students from all disciplines to pedagogical principles.

Challenging the status quo and convincing university officials to assume financial responsibility for a grant-funded instructional development program can be a daunting task. However, as Schein points out, "culture operates as a set of implicit and silent assumptions, which cannot change unless they are brought to the surface and confronted" (p. 306). "Research" universities, in particular, will never adequately support teaching and teaching programs until the place of teaching within the institution's mission and priorities is examined and teaching programs that are funded by soft money, fight hard for their place at the table. 


\section{References}

Bergquist, W.H. (1992). The four cultures of the academy: Insights and strategies for improving leadership in collegiate organizations. San Francisco: Jossey-Bass.

Berry, G., Jr. (1991, September). Planning for project continuation. Paper presented at the National Title III Workshop, Washington, DC (ERIC Document Reproduction Service No. ED 340 443).

Bina, J.V., \& Hull, W. L. (1978). Demonstration projects: Implementation and institutionalization. Columbus, $\mathrm{OH}$ : Ohio State University, National Center for Research in Vocational Education. (ERIC Document Reproduction Service No. ED 155 361).

Birnbaum, R. (1988). How colleges work: The cybernetics of academic organization and leadership. San Francisco: Jossey-Bass.

Bledsoe, G.B. (1994). Local associations and faculty development. Thought and Action: The NEA Higher Education Journal, 9(2), 41-49.

Bruenig, II, R.H. (1979). Proposals for change: A study of proposals to establish faculty development programs at five universities and one college of the California State University and Colleges. Unpublished doctoral dissertation, Union Graduate SchoolWest.

Conrad, C.F. (1978). A grounded theory of academic change. Sociology of Education, 51, 101-112.

Conrad, C.F., \& Wilson, R.F. (1985). Academic program reviews: Institutional approaches, expectations, and controversies. ASHE-ERIC/Higher Education Research Report No. 5, 1985. Washington, DC: Association for the Study of Higher Education.

Davis, W.E., \& Minnis, D.L. (1993) Designing a program to prepare graduate students for careers as college teachers. Innovative Higher Education, 17, 211-224.

Fleischman, H.L. (1980, December). Measuring impact of demonstration projects. (Contract No. 300-78-0574). Washington, DC: Department of Health, Education and Welfare, Office of Education. (ERIC Document Reproduction Service No. ED 194 807)

Fretz, B.R. (1993). The compleat scholar: Faculty development for those who teach psychology. In T.V. McGovern (Ed.) Handbook for Enhancing Undergraduate Education in Psychology (pp. 93-121). Washington, DC: American Psychological Association.

Gaff, J.G. (1994). Faculty development: The new frontier. Liberal Education, 80(4), 16-21.

Gaff, J.G., \& Simpson, R. (1994). Faculty development in the United States. Innovative Higher Education, 18, 167-176.

Gumport, P.J. (1993). The contested terrain of academic program reduction. Journal of Higher Education, 64, 283-311.

Hefferlin, J.B. (1969). Dynamics of academic reform. San Francisco: Jossey-Bass.

Hill, P.T. (1981). Follow through and the problem of federal education programs. Washington, DC: National Institute of Education, Office of Teaching and Learning. (ERIC Document Reproduction Service No. ED 244726). 
Jones, P., \& Lewis, J. (1991). Implementing a strategy for collective change in higher education. Studies in Higher Education, 16, 51-61.

Kaczynski, D.J. (1993, April). Condoning drug education programs at colleges and universities. Paper presented at the Annual Meeting of the American Educational Research Association, Atlanta, GA. (ERIC Document Reproduction Service No. ED 359 876)

Lambert, L.M. \& Tice, S.L. (Eds.) (1993). Preparing graduate students to teach: A guide to programs that improve undergraduate education and develop tomorrow's faculty. Washington, DC: American Association for Higher Education.

Levine, A. (1980). Why innovation fails. Albany, NY: State University of New York.

Lewin, K. (1951). Field theory in social science. New York: Harper \& Brothers.

Lindquist, J. (1974). Political linkage: The academic innovation process. Journal of Higher Education, 45, 323-343.

Lindquist, J. (1978). Strategies for change. Berkeley: Pacific Soundings.

Lindquist, J. (Ed.). (1979). Designing teaching improvement programs. Washington, DC: The Council for the Advancement of Small Colleges.

Marcus, D. (1990). Lessons learned from FIPSE projects. Washington, DC: U.S. Department of Education, Fund for the Improvement of Postsecondary Education.

Marcus, D., Cobb, E. B., \& Shoenberg, R. E. (1993). Lessons learned from FIPSE projects II. Washington, DC: U.S. Department of Education, Fund for the Improvement of Postsecondary Education.

Martorana, S. V., \& Kuhns, E. (1978, May) Analyzing a force for change: Discrepancy between aspiration and achievement of institutional goals. Paper presented at the annual Association of Institutional Research Forum, Houston, TX. (ERIC Document Reproduction Service No. ED 161336 )

Martorana, S. V., \& Kuhns, E. (1975) Managing academic change: Interactive forces and leadership in higher education. San Francisco: Jossey-Bass.

Mathis, C. (1979). The university center. In J. Lindquist (Ed.), Designing teaching improvement programs (pp. 91-127). Washington, DC: The Council for the Advancement of Small Colleges.

Millis, B.J. (1994). Faculty development in the 1990s: What it is and why we can't wait. Journal of Counseling \& Development, 72, 454-464.

Nordvall, R.C. (1982). The process of change in higher education institutions. (ASHEERIC/Higher Education Research Report No. 7, 1982). Washington, DC: American Association for Higher Education.

Reich, J.N. (1994). Developing faculty development programs: A view from the chair. Journal of Counseling \& Development, 72, 511-513.

Schein, E.H. (1985). Organizational culture and leadership. San Francisco: Jossey-Bass.

Seymour, D.T. (1988). Developing academic programs: The climate for change. (ASHEERIC/Higher Education Research Report No. 3, 1988). Washington, DC: Association for the Study of Higher Education. 
Tierney, W.G. (1988). Organizational culture in higher education. Journal of Higher Education, 59, 2-21.

Walsh, J.A., \& Meade, G.R. (September, 1981). The Alabama Information and Development System (AIDS): State dissemination capacity building grant. Final report. Montgomery, AL: Alabama State Department of Education, Division of Research and Information Services.(ERIC Document Reproduction Service No. ED 224 494).

Watson, G., \& Grossman, L.H. (1994). Pursuing a comprehensive faculty development program: Making fragmentation work. Journal of Counseling \& Development, 72,465-473.

Contact:

Mary Everley

Teaching Opportunities Program for Doctoral Students

University of Minnesota

1313 SE Fifth Street

University Technology Center, Suite 228

Minneapolis, MN 55414-1546 USA

(612) 627-4119

(612) 627-4349 FAX

ever1001@gold.tc.umn.edu

Mary Everley is a Teaching Consultant in the Preparing Future Faculty Program at the University of Minnesota - Twin Cities. Her responsibilities, in addition to teaching a practicum course for graduate students and consulting with program participants, include program evaluation and development. Everley's research interests and academic background lie in the area of higher education administration.

Jan Smith is Program Director for Preparing Future Faculty at the University of Minnesota - Twin Cities. Her twenty years of experience in graduate student teaching development and program administration in higher education has included work with numerous grants and soft money initiatives. She is currently a member of the POD Core Committee and in 1997 will chair Changing Graduate Education: The Sixth National Conference on the Education and Employment of Graduate Teaching Assistants. 